\section{Colourimetric capnometry to verify nasogastric tube placement in patients at risk of mal-placement}

\author{
Peggy PP Cheng ${ }^{1}$, RN, B App Sc (N), MHSc(Gerontology); Iris FK Lee ${ }^{2}, \mathrm{RN}, \mathrm{PhD}$
}

\section{ORIGINAL ARTICLE}

\author{
Peggy PP Cheng', RN, B App Sc (N), MHSc(Gerontology); Iris FK Lee², RN, PhD
}

\begin{abstract}
Background. Nasogastric tubes (NGT) are frequently used in geriatric settings and verification of NGT placement is important for patient safety. This study aimed to ascertain the accuracy of carbon dioxide $\left(\mathrm{CO}_{2}\right)$ colourimeter in the verification of NGT and to estimate the reduction in patient waiting time for resumption of NGT feeding in the general care setting.
\end{abstract}

Methods. Doubtful NGT placements were obtained from patients in three medical extended wards in a public hospital in Hong Kong. Doubtful NGT placements were verified using both $\mathrm{X}$-ray imaging and $\mathrm{CO}_{2}$ colourimeter. The sensitivity and specificity of $\mathrm{CO}_{2}$ colourimeter were evaluated using $X$-ray imaging as the gold standard. The patient waiting time for resumption of NGT feeding were estimated by recording the time required for completion of $X$-ray imaging verification.

Results. There were 26 patients in the study with a mean age of 74.07 years $(\mathrm{SD}=16.33)$. Fifteen $(57.7 \%)$ of them were male. The final sample consisted of 71 doubtful NGT placement and none of them was misplaced. The specificity of $\mathrm{CO}_{2}$ colourimeter was $98.6 \%$, while the sensitivity was unable to determine. The patient waiting time required for $\mathrm{X}$-ray imaging verification ranged from 51 to 1095 minutes (mean = 380.75 min., SD = 179.51).

Conclusions. $\mathrm{CO}_{2}$ colourimeter has high specificity in verification of doubtful NGT placement. Replacing X-ray imaging with $\mathrm{CO}_{2}$ colourimetry verification may speed up resumption of NGT feeding.

Key words: Carbon dioxide; Colorimetry; Intubation, gastrointestinal; Sensitivity and specificity

\author{
Yan Chai Hospital, Kowloon West \\ Cluster, Hospital Authority, Hong Kong \\ 2 Nethersole Institute of Continuing \\ Holistic Health Education, Alice Ho Miu \\ Ling Nethersole Charity Foundation, \\ Hong Kong
}

Correspondence to: Ms Peggy Po Po Cheng, Yan Chai Hospital, Kowloon West Cluster, Hospital Authority, Hong Kong. Email: chengpp@ha.org.hk

\section{BACKGROUND}

Nasogastric tubes (NGT) are frequently used in patients who are unable or unsafe to feed orally or have inadequate nutritional support. Nurses are responsible for insertion and management of the tubes. Tube misplacement into the lung is a complication with severe consequences.

The Joanna Brigg Institute recommends the use of various bedside methods individually or in combination to assess NGT placement. ${ }^{1-3}$ However, the reliability of these methods to differentiate pulmonary from gastric placement is unacceptable.
These methods include observing patient's response such as coughing and choking, auscultating of air insufflated through the tube, and observing for bubbling when the tip end is immersed in water. Radiography is the gold standard for checking NGT placement, whereas $\mathrm{pH}$ checking of gastric aspirate is considered the second most reliable test. Nevertheless, both methods may not be applicable in all care settings. For example, a $\mathrm{pH}$ value of $\leq 5.5$ suggests that the NGT is in the stomach. However, the $\mathrm{pH}$ value may be $\geq 6$ when the patient is taking antacids and acid inhibitors or in some cases no gastric aspirate can be obtained from the tube. When these occur, radiography is recommended for 
confirmation, ${ }^{3}$ but this is impractical or impossible in some institutions and community aged homes.

Radiographic confirmation of the NGT placement is not $100 \%$ reliable and may lead to misinterpretations by inexperienced personnel. ${ }^{4}$ Other problems include delayed feeding owing to the time required for taking radiographs and for interpretation and radiation exposure.

Colourimetric capnometry of carbon dioxide $\left(\mathrm{CO}_{2}\right)$ is reliable for detecting NGT insertion into the airway, ${ }^{5-10}$ with sensitivity of $88 \%$ to $100 \%$ and specificity of $99 \%$ to $100 \% .{ }^{10}$ It is safe, easy to use, and efficient. ${ }^{7}$ However, it has lower sensitivity $(80 \%)$ and specificity $(86.5 \%)$ in the general adult ward setting. ${ }^{11}$ This study aimed to determine the accuracy of colourimetric capnometry in verifying NGT placement in a general care setting.

\section{METHODS}

This study was approved by the Kowloon West Cluster Research Ethics Committee (KW/EX18-108(127-04)). Written informed consent was obtained from each patient or the patient's guardian before data collection. Patients aged $\geq 18$ years with an NGT insertion at three medical extended care wards of a general public hospital were invited to participate between December 2018 and May 2019. Patients were included when aspirates from NGT contained no gastric fluid, had $\mathrm{pH}$ of $\geq 6$, and were tan to off-white. Patients were excluded when they had gastric aspirate of $\mathrm{pH} \leq 5.5$, were on continuous enteral feeding, had the NGT insertion for stomach lavage, washout, or gastric aspiration for bleeding monitoring, or were receiving any intensive medical intervention such as ventilator care and active resuscitation care.

Colourimetric capnometry of $\mathrm{CO}_{2}$ was performed by nurses at bedside using the Easycap II adult $\mathrm{CO}_{2}$ Detector. The NGT placement was checked through epigastric auscultation using the whoosh test. Supplement methods included checking coiling of the NGT inside the mouth, checking the NGT marking, and checking the patient's appearance and respiration pattern. The NGT was then connected by a syringe and flushed in $10 \mathrm{~mL}$ of air to clear any blockage. If the sound was clear, the syringe was removed, and the colourimetric capnometry was connected to the end of the NGT with a designated adaptor. The colour reading was checked after at least six breaths or 1 minute, $^{13}$ as the ventilating rate for normal adults is about 12 to 20 breaths per minute, with exhaled $\mathrm{CO}_{2}$ of 35 to $45 \mathrm{mmHg} .{ }^{12} \mathrm{~A}$ change of colour from purple to yellow or brown indicates the presence of an end-tidal $\mathrm{CO}_{2}$ of $>15 \mathrm{mmHg}$ (Figure). The NGT placement was confirmed with radiography and by the on-call physician before resumption of feeding. In addition, the waiting time from NGT insertion to radiography, the waiting time from radiography to resumption of NGT feeding, and the total waiting time were recorded.

Sensitivity and specificity of colourimetric capnometry were calculated with reference to radiographic findings. A $p$ value of $<0.05$ was considered statistically significant.

\section{RESULTS}

Of 40 eligible patients, 32 gave written informed consents. Of them, 26 (15 men and 11 women) aged 33 to 97 (mean, 74.07) years had 71 episodes of doubtful NGT placement (49 silicone tubes and 22 polyvinyl chloride tubes) owing to lack of aspirate after NGT insertion (TABLE 1). Epigastric auscultation was negative in five (7\%) episodes. Most patients experienced only one insertion attempt, and a few experienced 2 to 3 insertion attempts. One patient experienced 10 insertion attempts because the NGT was coiled in the throat or regurgitated out by the patient.

Colourimeter indicated negative detection of $\mathrm{CO}_{2}$ in 70 of 71 episodes, which were confirmed by radiography and by the on-call physician that the NGT end was underneath the diaphragm (suggesting

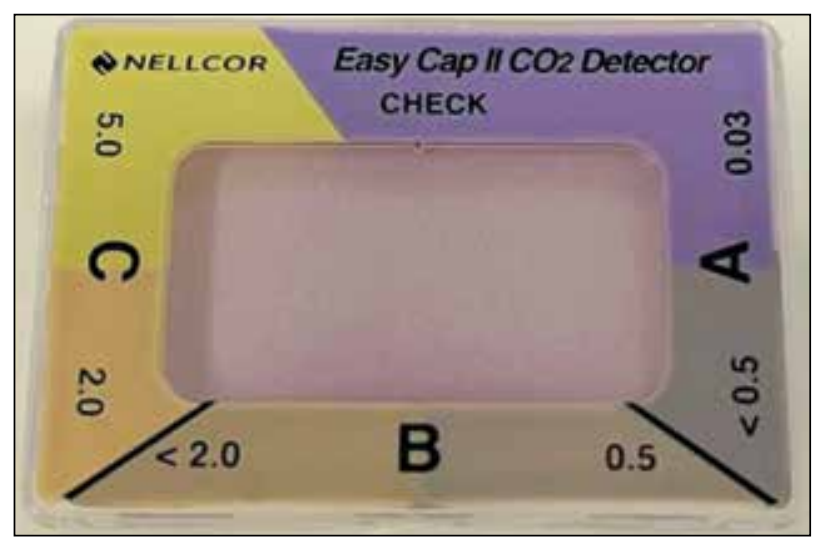

FIGURE. Three zones of end-tidal carbon dioxide levels in the colourimeter: A (range, $0.03 \%$ to $<0.5 \%$ ) [ $<4 \mathrm{mmHg}$ ], B (range, $0.5 \%$ to $<2 \%$ ) [ 4 to $<15 \mathrm{mmHg}$ ], and $\mathrm{C}$ (range, $2 \%$ to 5\%) [15 to $38 \mathrm{mmHg}]$ 
inside the stomach). Hence, the specificity of the colourimeter to confirm NGT placement was $98.6 \%$, and the negative predictive value (accuracy to rule out tracheobronchial insertion) was $100 \%$. However, as none of the episodes was true positive, the sensitivity and positive predictive value of the colourimeter were undetermined. The only episode with false-positive detection of $\mathrm{CO}_{2}$ by the colourimeter occurred after 10 insertion attempts of the NGT. However, the NGT was confirmed to be in the gastro-intestinal tract by radiography.

The mean waiting time from NGT insertion to radiography was $223.82 \pm 159.82$ (range, 27-795) minutes. The mean waiting time from radiography to resumption of NGT feeding was $158.20 \pm 93.88$ (range, 11-367) minutes. Thus, the mean total waiting time was $380.75 \pm 179.51$ (range, 51-1095) minutes. Of the 71 episodes, $78.9 \%$ needed to wait for $>4$ hours to resume NGT feeding (TABLE 2).

TABLe 1

Characteristics of patients $(n=26)^{*}$

\begin{tabular}{lc}
\hline Age, y & $74.07 \pm 16.33(33-97)$ \\
$\geq 65$ & $23(88.5)$ \\
$<65$ & $3(11.5)$ \\
Sex & \\
Male & $15(57.7)$ \\
Female & $11(42.3)$ \\
Comorbidity & \\
Cerebrovascular accident & $18(69.2)$ \\
Hypertension & $11(42.3)$ \\
Diabetes mellitus & $9(34.6)$ \\
Dementia & $6(23.1)$ \\
Heart disease & $4(15.4)$ \\
Parkinson disease & $3(11.5)$ \\
\hline
\end{tabular}

* Data are presented as mean \pm standard deviation (range) or no. (\%) of patients

\section{DISCUSSION}

The high specificity of $98.6 \%$ indicated that colourimeter capnometry can be an alternative of radiography to confirm NGT placement. ${ }^{10}$ However, its sensitivity and positive predictive value was undetermined because none of the episodes was true positive, which may be related to the careful testing of the NGT placement by the epigastric auscultation whoosh test before colourimeter capnometry. ${ }^{7}$ Hence, a combination of epigastric auscultation with colourimetric capnometry to verify doubtful NGT placement is recommended.

The only false positive case may be due to trapping of $\mathrm{CO}_{2}$ inside the NGT after repeated insertion attempts of the NGT owing to patient regurgitation. Hence, a sufficient time should be allowed to let out the trapped $\mathrm{CO}_{2}$ before connecting to the colourimeter. The colour of the colourimeter reversed from yellow to purple when it is left in room air for 10 minutes. The device supports constant visual feedback within 2 hours; it can be re-used for $\mathrm{CO}_{2}$ analysis in the same patient.

Although radiographic confirmation of NGT placement prior to patient feeding ensures patient safety, the waiting time until resumption of NGT feeding is too long. The processes involve seeking medical support to prescribe a request for radiography, waiting for radiographic investigation, and pending for physician interpretation of the results. Patients may be at risk of dehydration owing to delayed feeding. The waiting time may be longer if patients are living in the community, because patients have to wait for ambulance transportation to the accident and emergency department for radiographic examination and physician interpretation of the results of the NGT placement. Therefore, $\mathrm{CO}_{2}$ colourimeter test together with

TABLE 2

Waiting time from nasogastric tube (NGT) insertion to resumption of NGT feeding in 71 episodes

\begin{tabular}{lccc}
\hline Waiting time, hours & $\begin{array}{c}\text { Waiting time from NGT insertion } \\
\text { to radiography* }\end{array}$ & $\begin{array}{c}\text { Waiting time from radiography to } \\
\text { resumption of NGT feeding }\end{array}$ & Overall waiting time* $^{*}$ \\
\hline & $223.82 \pm 159.82(27-795)$ minutes & $158.20 \pm 93.88(11-367)$ minutes & $380.75 \pm 179.51(51-1095)$ minutes \\
$<1$ & $5(7.0)$ & $5(7.0)$ & $1(1.4)$ \\
$1-4$ & $35(49.3)$ & $50(70.4)$ & $14(19.7)$ \\
$>4-6$ & $20(28.2)$ & $14(19.7)$ & $11(15.5)$ \\
$>6-8$ & $8(11.3)$ & $2(2.8)$ & $31(43.7)$ \\
$>8$ & $3(4.2)$ & - & $14(19.7)$ \\
\hline
\end{tabular}

* Data are presented as mean \pm standard deviation (range) or no. (\%) of episodes 
epigastric auscultation whoosh test may speed up resumption of NGT feeding and reduce healthcare manpower.

One set of $\mathrm{CO}_{2}$ colourimeter costs $\mathrm{HK} \$ 137$ and a reusable adaptor costs $\mathrm{HK} \$ 28$. The colourimeter can be re-used by the same patient for NGT insertion. The overall costs of colourimetric capnometry is lower than those of radiographic examination, which involves manpower on transportation service, physician interpretation of the results, and nursing manpower on coordination. For patients living at home or residential care home, extra cost is incurred in admission for radiographic examination via the accident and emergency department.

The present study has limitations. It was conducted in three medical extended wards of a single hospital. The long waiting time may be biased by the restricted medical support and radiographic service and thus may not be generalised to other hospital settings. The sample size was small. Further studies with larger samples at different settings are warranted.

\section{CONCLUSION}

A combination of epigastric auscultation whoosh test and colourimeter capnometry is reliable to rule out NGT tracheal or bronchial insertion. Colourimeter capnometry is safe, easy to perform, and provides a clear-cut result, especially when radiographic examination is not accessible. It saves waiting time and money for radiographic examination and interpretation and minimise patient exposure to unnecessary radiation.

\section{CONTRIBUTORS}

All authors designed the study, acquired the data, analysed the data, drafted the manuscript, and critically revised the manuscript for important intellectual content. All authors had full access to the data, contributed to the study, approved the final version for publication, and take responsibility for its accuracy and integrity.

\section{CONFLICTS OF INTEREST}

All authors have disclosed no conflicts of interest.

\section{FUNDING/SUPPORT}

This study received support from Yan Chai Hospital
Medical Fund.

\section{DATA AVAILABILITY}

All data generated or analysed during the present study are available from the corresponding author on reasonable request.

\section{ETHICS APPROVAL}

The study was approved by Kowloon West Cluster Research Ethics Committee (Ref: KW/EX-18108(127-04)). The patients were treated in accordance with the tenets of the Declaration of Helsinki. The patients provided written informed consent for all treatments and procedures.

\section{ACKNOWLEDGEMENT}

We thank all nurses who participated in this study.

\section{REFERENCES}

1. Chau JP, Lo SH, Thompson DR, Fernandez R, Griffiths R. Use of end-tidal carbon dioxide detection to determine correct placement of nasogastric tube: a meta-analysis. Int J Nurs Stud 2011;48:513-21. Crossref

2. Nasoenteric Feeding (Older Person): Tube insertion. Joanna Briggs Institute (JBI) Recommended Practice 2016.

3. Nasoenteric Feeding: Tube insertion. Joanna Briggs Institute (JBI) Evidence Summary, 2017.

4. Donaldson L, Panesar S. Nasogastric tube errors. Medical Protection Society 2017; https://www.medicalprotection.org/uk/ articles/nasogastric-tube-errors. Accessed 18 June 2020.

5. Burns SM, Carpenter R, Blevins C, et al. Detection of inadvertent airway intubation during gastric tube insertion: capnography versus a colorimeter carbon dioxide detector. Am J Crit Care 2006;15:188-95. Crossref

6. Elpern EH, Killeen K, Talla E, Perez G, Gurka D. Capnometry and air insufflation for assessing initial placement of gastric tubes. Am J Crit Care 2007;16:544-9. Crossref

7. Meyer P, Henry M, Maury E, Baudel JL, Guidet B, Offenstadt G. Colorimeter capnography to ensure correct nasogastric tube position. J Crit Care 2009;24:231-5. Crossref

8. Ryu JA, Choi K, Yang JH, et al. Clinical usefulness of capnogrphic monitoring when inserting a feeding tube in critically ill patients: retrospective cohort study. BMC Anesthesiol 2016;16:122. Crossref

9. Erzincanli,S, Zaybak A, Guler A. Investigation of the efficacy of colorimetric capnometry method used to verify the correct placement of the nasogastric tube. Intensive Crit Care Nurs 2017;38:46-52. Crossref

10. Bennetzen LV, Håkonsen SJ, Svenningsen H, Larsen P. Diagnostic accuracy of methods used to verify nasogastric tube position in mechanically ventilated adult patients: a systematic review. JBI Database System Rev Implement Rep 2015;13:188-223. Crossref

11. Mordiffi SZ, Goh ML, Phua J, Chan YH. Confirming nasogastric tube placement: is the colorimeter as sensitive and specific as X-ray? A diagnostic accuracy study. Int J Nurs Stud 2016;61:24857. Crossref

12. Duckworth RL. How to read and interpret end-tidal capnography waveforms. J Emerg Med Serv 2017;42.

13. US Food and Drug Administration. MAUDE Adverse Event Report: COVEDIEN/FORMERLY TYCO NELLCOR EASY CAP II CO2 DETECTOR. 